\title{
Assessment of Genetic Capability for Post-Weaning Growth Traits of Reciprocal Cross between Gabali and V-Line Rabbits Using an Animal Model
}

\author{
Tarik Rabie $^{1 *}$, Amira Nowier ${ }^{2}$, Adel Abou-Zeid ${ }^{3}$ and Adel Khattab ${ }^{3}$ \\ ${ }^{1}$ Animal Production Department, Faculty of Agriculture, Suez Canal University, Ismailia, 41522, Egypt. \\ ${ }^{2}$ Animal Production Research Institute, Agriculture Research Center, Ministry of Agriculture, Egypt. \\ ${ }^{3}$ Tanta University, Faculty of Agriculture, Animal Production Department, Egypt. \\ *Corresponding author's Email: tarik.rabie@agr.suez.edu.eg; (D) ORCiD: 0000-0001-9678-2323
}

\begin{abstract}
This study aimed to assess the conceivable impact of hereditary factors on the crossbreeding rabbit groups set up by proportional going between Sinai Gabali and V-Line. Reciprocal cross on the post-weaning performances was performed by estimating the genetic capability for their crosses. The study samples included two pure rabbit breeds (a male Saini Gabali (G) and a female V-Line (V)), and reciprocal crosses to compromise 10 groups. Records of 448 kits delivered by 45 does and 16 bucks were utilized to estimate Heritability $\left(h^{2}\right)$, genetic and phenotypic correlations, and breeding values of litter weight traits. First generation was created from the consequences of four parities $(1 / 2 \mathrm{G} 1 / 2 \mathrm{~V}$, and $1 / 2 \mathrm{~V} 1 / 2 \mathrm{G}$; sire breed was demonstrated first). Weaning was implemented on the 28th day of the kits' age. Post-weaning litter traits were measured Body weight $(\mathrm{BW})$ at 4, 5, 6, 8, 10, and 12 weeks of their age; and average daily gain was measured during 4-8 weeks $\left(\mathrm{ADG}_{4-8}, \mathrm{ADG}_{4-12}, \mathrm{ADG}_{8-10}\right.$, and $\left.\mathrm{ADG}_{8-12}\right)$. Data were examined by animal model, which was performed utilizing derivate free limited maximum likelihood. The results revealed that $h^{2}$ was moderate for both breeds, and its reciprocal cross ranged from 0.2 to 0.25 , and BW at weaning was $0.22 \pm 0.07$. Meanwhile, there was a positive genetic correlation between BW and ADG at different age ranges (ranged 0.02 to $0.77,0.04$ to 0.76 , respectively). Assessments of environmental correlation between BW at different age ranges were negative, except of those between $\mathrm{BW}_{8}$ and $\mathrm{BW}_{12}$ which were positive, but not significant. Additionally, the progeny had higher predicting breeding values for BW at 4, 8,10, and 12 weeks for both breeds, but that was obtained from $\mathrm{G} \times \mathrm{V}$ exceeding those from their reciprocal cross. In conclusion, direct additive variance was considerably effective, and consequently body weight at weaning and post-weaning growth traits could be improved by utilizing bucks of Sinai Gabali with doesof V-line based on the performance of their progenies, and selection of sires and dams.
\end{abstract}

Keywords: Genetic correlation, Heritability, Post-weaning, Sinai gabali, V-line, Weaning weight

\section{INTRODUCTION}

The expected global needs for the meat at 2050 are about $73 \%$ compared to present mass production. The developing countries will contribute for most of this expansion due to fast population growth and ascending of capital income (FAO, 2011; OECD, 2017). Obike and Ibe (2010) conveyed that rabbits are considered as a high-quality source of protein with cheap price, which can be used to improve the animal production of protein in low revenue populations (Makkar et al., 2014). Furthermore, the rabbits had many compensations above other animals for low cost meat production, for instance, high growth rate, high feed conversion, and their ability to utilize fibrous feeds, both of sexual maturity and short gestation length resulted in a short generation interval, also, the rabbits' meat was classified as a high-quality meat (Herbert, 2011). In addition, growth rate in rabbits, particularly their post-weaning was intensely affected by genotype and environmental condition including the availability of both quality and quantity of feed. Furthermore, the diversity of the rabbit breeds gave more opportunities to improve the meat production by divergent breeds crossing (Piles et al., 2004).

Heritability, which is an element of variance components, gave data about the hereditary idea of a characteristic and is required for genetic assessment and selection procedures (El-Raffa, 2005). Phenotypic variance assumed a vital part for post-weaning traits in rabbits was generally depicted to be overwhelmed by ecological impacts inferable from the does or potentially litter, which might owe the short interval from the weaning to marketing. Moreover, low heritability and direct proportions of genetic responses to select for post-weaning growth traits were conveyed (Lukefahr 
et al., 1996). The rabbits' genetic improvements were mainly conditional on the heritability of the defined traits, and its association with different other traits of economic importance were measured. A moderate to high heritability (0.7-0.9) for litter weight at 7-8 weeks old, while the repeatability generally indicating low estimates (0.003-0.008) were obtained by Okoro et al. (2012). In oppose with Iraqi, 2008 who found that estimating of heritability were 0.05 to 0.38 body weight $(\mathrm{BW})$ at 4,8 , and 12 weeks old, while these estimations were 0.23 and 0.19 for daily gain from 4 to 8 , and 8 to 12 weeks of age, correspondingly. Though, additive genetic variability was far from being considered negligible. To facilitate, and to make rapid improvements in rabbits' performance, it could be inaugurated from selection and use of divergent breeds in the crossbreeding (Chineke and Raheem, 2009). In addition, crossbreeding is efficient for improving the post-weaning growth potential (Piles et al., 2004). Besides, selection in maternal lines in rabbit was somewhat considering determination inside limited population which amassed in mating grouping impacts (Ragab et al., 2015), extending the hereditary variety amongst lines and, verifiably, changing the gene frequencies between population. Furthermore, to employ genetic resources effectively, the genetic and environmental causes of phenotypic alteration in economic attributes need to be differentiated (Gorbani and Salamatdoust, 2011). The intention of rabbits' breeding was to improve execution characteristics of rabbits' population through both mating and selection. Accordingly, the targets of the existing research were to assess conceivable impact of hereditary factors on crossbreeding rabbit groups set up by proportional going between Sinai Gabali and V-Line (as a unique lines) by reciprocal cross on post-weaning performances by estimate the genetic capability for their crosses.

\section{MATERIALS AND METHODS}

\section{Ethical approval}

The experiment was carried out according to the National Regulations on Animal Welfare and Institutional Animal Ethics Committee, Egypt.

\section{Breeding plan}

Two pure rabbit breeds were used in current study (Saini Gabali (G), and V-Line (V) as a standard exotic line). Does and bucks of the $\mathrm{V}$ were acclimatized descendants of the Spanish synthetic line. Crossbreeding system was applied in ten mating groups which contained 4 to 5 does per group. The first five groups consisted of $\mathrm{V}$ does which were mated

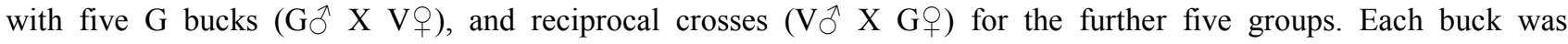
represented as a sire to all litters in each group to produce $F_{1}\left(1 / 2 \mathrm{G}^{1 / 2} \mathrm{~V}\right.$ and $1 / 2 \mathrm{~V} 1 / 2 \mathrm{G}$; sire breed was indicated first). Weaning was implemented at 28 days of kits' age.

\section{Rabbitry, housing and management}

Animals were raised in a semi closed rabbitry, depending on the natural ventilation. Does were housed individually in pens where there were settle boxes, feeders, and automatic drinkers. All rabbits were fed on a commercial lactatingpelleted-diet containing approximately $2600 \mathrm{Kcal} / \mathrm{kg}$ ration as digestible energy; $16.3 \%$ crude protein; $13.2 \%$ crude fiber and $2.5 \%$ fat. Both of feed and water were provided ad libitum. Does mated their same respective group assigned bucks 10 days post-kindling. Pregnancy was ascertained by palpation 10 days of succeeding mating. Females that neglected to conceive were come back to the same assigned buck to be re-reproduced. Inside 12 hours once encouraging, litters were checked and recorded. In this way, weaned a month kits were sexed and exchanged for additional study to standard descendants prepared pens.

\section{Source of data}

Post-weaning litter traits were body weight $\left(\mathrm{BW}_{4}\right)$ at , 5, 6, 8, 10, and 12 weeks old, average daily gain between 4 to 8 weeks $\left(\mathrm{ADG}_{4-8}\right), 4$ to 12 weeks $\left(\mathrm{ADG}_{4-12}\right), 8$ to 10 weeks $\left(\mathrm{ADG}_{8-10}\right)$, and 8 to 12 weeks $\left(\mathrm{ADG}_{8-12}\right)$.

\section{Statistical analysis}

Linear model

Data were preliminary analyzed using general linear model (GLM) and VARCOMP procedures of Statistical Analysis System (SAS, 2001, version 8.1). In addition, single and multi-traits animal model analyses (AM), were performed using derivate free restricted maximum likelihood as recommended by Boldman et al. (1995). For the derivative- free model, convergence (co) variance components estimation was when the global maximum of the log likelihood function was found.

Estimation of heritability $\left(h^{2}\right)$

The following formula was used by the animal model software to estimate $h^{2}$ 
$h^{2}=\frac{\sigma^{2} a}{\sigma^{2} a+\sigma^{2} P_{e}+\sigma^{2} e}$

Where,

$\sigma^{2} a$ : was additive genetic variance $\sigma^{2} P_{e}$ : was permanent environmental variance, and $\sigma^{2} e$ : were random residual associated with each observation.

\section{Estimation of correlations}

The following formula was used as recommended by Franzese and Iuliano (2019).

$r_{X Y}=\frac{\operatorname{cov}(x y)_{i j}}{\sqrt{\sigma^{2} x i j} \sqrt{\sigma^{2} y_{i j}}}$

Where,

$\operatorname{cov}(x y)_{i j}=$ The additive genetic covariance, $\sigma^{2} x i j=$ The additive genetic variance of the trait (or permanent environmental, environmental and phenotypic). $\sigma^{2} y_{i j}=? ? ? ? ?$

\section{Estimation of Predicted breeding value}

The mixed model equations (MME) for the best linear unbiased estimator (BLUE) of Estimable function of $b$, and for the BLUP of $a$ and pe, in matrix notation was as follows:

$\left[\begin{array}{lll}X^{\prime} X & X^{\prime} Z & X^{`} w \\ Z^{\prime} X & Z^{`} Z+A^{-1} \alpha_{1} & Z^{`} Z \\ \mathrm{~W}^{`} X & w^{`} Z & w^{\prime} w+I \alpha_{2}\end{array}\right]\left[\begin{array}{l}b^{\wedge} \\ a^{\wedge} \\ p^{\wedge}\end{array}\right]=\left[\begin{array}{l}X y^{`} \\ Z y^{`} \\ w y^{`}\end{array}\right]$

Where, $\mathrm{A}^{-1}$ is the inverse of the numerator relationship matrix,

$\alpha_{1=} \sigma_{\mathrm{e}}^{2} / \sigma_{\mathrm{a}}^{2}$ and $\alpha_{2}=\sigma_{\mathrm{e}}^{2} / \sigma_{\mathrm{pe}}^{2}$

\section{Estimation of Accuracy of Predicted breeding value}

The accuracy of predicted breeding values for each animal was assessed as follows:

$\mathrm{R} \mathrm{A}^{\prime} \mathrm{A}=\left(1-\mathrm{d}_{\mathrm{j}} \mathrm{a}\right)^{2}$,

Where,

R A $\mathrm{A}=$ the accuracy of prediction of the individual breeding values, $\mathrm{d}_{\mathrm{j}}=$ the ${ }_{\mathrm{j}}$ th diagonal elements of inverse of the appropriate block coefficient matrix standard error, $(\mathrm{Se})$ was estimated by the following relation: $\mathrm{Se}=\mathrm{d}_{\mathrm{j}} \sigma^{2}{ }_{\mathrm{e}}$. In addition, simple correlations between breeding values for litter traits and progeny weight were estimated.

\section{RESULTS AND DISCUSSION}

\section{Heritability estimates for body weight and average daily gain}

Heritability estimates $h^{2}$ for BW at $4,6,8$, and 12 weeks were $0.65 \pm 0.169,0.09 \pm 0.224,0.01 \pm 0.118$ and $0.29 \pm$ 0.143 , respectively which were estimated from MTAM, and using all data. $h^{2}$ are moderate for both breeds and ranged

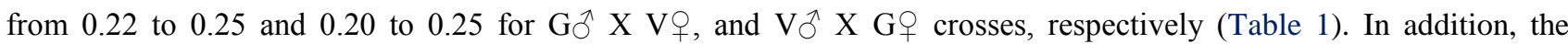

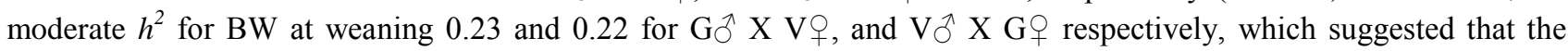
selection for weaning weight will give greater improvement for $\mathrm{BW}$ at marketing, thus, this could be situated as the endorsement goal of animal breeder. Furthermore, a little higher $h^{2}$ of BW for $\mathrm{G}{ }^{\lambda} \mathrm{X} \mathrm{V} \bigcirc$ than its reciprocal indicated the importance of using bucks of Saini Gabali to improve BW at different ages.

The extant results indicated that $h^{2}$ estimates were higher for BW at weaning and decreased gradually, and then increased at older ages. The equivalent results were confirmed by Khalil (1986). Also, the moderate $h^{2}$ for $\mathrm{BW}_{4}$, and $\mathrm{BW}_{12}$ suggested that the selection for weaning weight will give a greater improvement in BW at marketing. Similarly, according to El-Kelany (2005) who concluded that the additive genetic variances at younger age (4 weeks) for the five breeds (New Zealand White, California, Basucat, Flander and Black and Baladi) were beneath those at older age ( 8 weeks). This could be a direct result of non-added substance of genetic impacts and changeless environmental impacts at 4 weeks than at 8 weeks. In addition, Anous (2000) found that $h^{2}$ estimates for BW at 4, 6, 8 and 10 weeks old were $0.67,0.81,0.98$ and 0.67 , respectively, and concluded that the selection for BW at earlier ages may be convenient procedure for improving early rabbit growth. The present estimate of $h^{2}$ for weaning weight were exceeding those reported before (0.224-0.26) (Argente et al., 1999; García and Baselga, 2002). These differences among results may be attributed to differences in sampling errors, available number of observations, methods of analysis and statistical model used. Contritely, low $h^{2}$ for BW at various ages of California were 0.17 and 0.18 for 8 and 12 weeks old, while $h^{2}$ were 
0.16 and 0.19 for daily gain during the period of 4 to 8 and 8 to 12 weeks old, respectively (Gharib, 2008). At the present study, the favorable estimates of $h^{2}$ for post-weaning growth traits were underneath those obtained by other scientists using the AM ranged from 0.30 to 0.72 (Iraqi et al., 2002). The acquired outcomes were correspondingly to the small sample' size of progeny per generation, second the inadequacy of progeny per sire, and third to the non-randomness in the allocation of progeny within sire group and sampling errors (Khalil et al., 2000). Intestinally, it will be an encouraging factor to enrich growth performance of these standard breeds raised in hot climates through the selection of sires in future. Regarding to gain weight, the present estimates of ADG among different ages were lower than those reported by many authors working on various rabbits' breeds and ranged from 0.018 to 0.61 . These results implied that the post-weaning ADG tends to be low to moderate heritable. Alike body weights, the $h^{2}$ for post-weaning ADG estimated from sire components were inferior to those estimated from dam components, which it was due to the maternal effect on BW from birth to weaning. These results corresponded to the previous studies where maternal genetic effects were realized significantly positive for the favors of V-Line dams, $\mathrm{BW}_{8}$ and $\mathrm{BW}_{12}$ (Abou Khadiga et al., 2008). The Vline had an unfavorable maternal genetic effect on the BW at 32 days old (ranging from 54.3 to 86.0 gram). In addition, Orengo et al. (2009) reported that maternal genetic effects were significant for BW at 60 days. Furthermore, the estimate of $h^{2}$ was higher for $\mathrm{BW}_{8}$ weeks than other ages, and the selection of the animals would be more effective at 8 weeks of age to improve post-weaning growth traits in Gabali rabbits (Iraqi, 2008).

Table 1. Estimates of heritability for body weights, and average daily gains from weaning to marketing weight for Gabali X V-line, and its reciprocal cross by animal model

\begin{tabular}{|c|c|c|c|}
\hline \multirow[b]{2}{*}{ Traits } & \multicolumn{3}{|c|}{ Heritability $\left(h^{2} \pm \mathrm{SE}\right)$} \\
\hline & All data & $\begin{array}{c}\text { Gabali x V- line } \\
\left(\mathbf{G}^{\lambda} \mathbf{X} \mathbf{V}+\right)\end{array}$ & $\begin{array}{c}\text { V- line x Gabali } \\
\left(\mathbf{V}{ }^{\lambda} \mathbf{X} \text { G }\right.\end{array}$ \\
\hline BW4 & $0.65 \pm 0.16$ & $0.23 \pm 0.07$ & $0.23 \pm 0.07$ \\
\hline $\mathbf{B W}_{6}$ & $0.09 \pm 0.22$ & $0.25 \pm 0.10$ & $0.25 \pm 0.10$ \\
\hline $\mathbf{B W}_{8}$ & $0.01 \pm 0.11$ & $0.25 \pm 0.05$ & $0.25 \pm 0.05$ \\
\hline $\mathrm{BW}_{12}$ & $0.29 \pm 0.14$ & $0.22 \pm 0.02$ & $0.22 \pm 0.02$ \\
\hline $\mathbf{A D G}_{4-8}$ & $0.01 \pm 0.13$ & $0.36 \pm 0.135$ & $0.15 \pm 0.135$ \\
\hline $\mathbf{A D G}_{4-12}$ & $0.12 \pm 0.06$ & $0.38 \pm 0.069$ & $0.61 \pm 0.069$ \\
\hline $\mathbf{A D G}_{8-12}$ & $0.08 \pm 0.05$ & $0.08 \pm 0.055$ & $0.04 \pm 0.055$ \\
\hline
\end{tabular}

BW: Body weight at 4, 6, 8, and 12 weeks of age (BW4, BW6, BW8, and BW12, respectively). ADG $_{4-8}$ : Average daily gain between 4-8 weeks interval, 4-12 weeks $\left(\mathrm{ADG}_{4-12}\right)$, and 8-12 weeks $\left(\mathrm{ADG}_{8-12}\right)$

\section{Genetics and environmental correlations}

The MTAM analysis of variance and covariance were performed on the data of V-Line and Saini Gabali breed to derive estimates of direct additive genetic $\left(r_{g}\right)$ and environmental correlations $\left(r_{e}\right)$ among different traits studied. Genetic correlation for both BW and ADG at distinctive ages were positive, and ranged from 0.02 to 0.77 , and 0.04 to 0.76 , respectively. The highest genetic correlation was 0.76 between $\mathrm{ADG}_{4-12}$ and $\mathrm{ADG}_{8-10}$ (Tables 2 and 3). These results possibly explained by that the selection for higher BW at weaning would cause an associated increase in marketing body weight. Assessments of environmental correlation among BW at different ages were negative, except the $r_{e}$ between $\mathrm{BW}_{8}$, and $\mathrm{BW}_{12}$ were positive $(0.08,0.124)$, but not significant (Table 2). Also, $\mathrm{r}_{\mathrm{e}}$ among ADG in different intervals were lower in most incidents than the genetic correlation (Table 3). The present findings advocated that using early information for higher BW selection at weaning would cause a correlated increase in marketing BW. Comparable results were acquired where $r_{g}$ ranged from 0.31 to 1.0 (El-Kelany, 2005; Khalil et al., 2000). Moreover, Shebl et al. (1997) stated that $r_{g}$ amongst BW at 8, 12 and 16 weeks of age, and the daily gain (8 and 12 weeks) for New Zealand White $(\mathrm{NZW})$ and Gabali line $(\mathrm{G})$ were positive. The current estimates of $\mathrm{r}_{\mathrm{g}}$ indicated that $\mathrm{BW}_{8}$ was more correlated than $\mathrm{BW}_{4}$, and $\mathrm{BW}_{6}$ compared to $\mathrm{r}_{\mathrm{g}}$ for $\mathrm{BW}_{4}$ with that at $\mathrm{BW}_{6}$, and $\mathrm{BW}_{12}$, indicating that high weaning weight was associated with heavier body weight as $\mathrm{BW}_{4}$, and $\mathrm{BW}_{12}$. Enab et al. (2000) found that $\mathrm{r}_{\mathrm{g}}$ were positive and generally high in Cal and NZW breeds at all ages $\left(4,8\right.$, and 12 weeks). Also, it was noted that $r_{g}$ in general tended to diminish the value as the intervals between two ages increased in both breeds (Enab et al., 2000). Prospectively, $r_{g}$ between ADG in different ages were positive; the highest $\mathrm{r}_{\mathrm{g}}$ between $\mathrm{ADG}_{4-12}$ and $\mathrm{ADG}_{8-10}$ indicated that the selection of animals that have heavy $\mathrm{BW}$ at 4 weeks of age, would increase BW at marketing in the next generation. Analogously, Shebl et al. (1997) found that the $\mathrm{r}_{\mathrm{g}}$ between $\mathrm{BW}_{8}$, and $\mathrm{ADG}_{8-12}$ weeks was lower than the corresponding $\mathrm{r}_{\mathrm{g}}$ between $\mathrm{BW}_{12}$ and $\mathrm{ADG}$ in the same period. Regarding to estimates of environmental correlation $\left(r_{e}\right)$ concerning $B W$ at different ages were negative, except for $r_{e}$ between $\mathrm{BW}_{8}$ and $\mathrm{BW}_{12}$ which was positive, but not significant. In addition, $\mathrm{r}_{\mathrm{e}}$ between average daily gains in different ages were lower than the genetic correlation in most incidents (Table 3). In other incidents, both $r_{g}$ and $r_{e}$ had the same indication, and they were not distinct in magnitude. Accordingly, this tendency might possibly be owing to several physiological mechanisms. 
Table 2. Estimates of genetic (above diagonal) and environmental (below diagonal) correlations among weekly body weights from weaning to marketing weight in rabbits as estimated by Multi-trait animal model

\begin{tabular}{lcccc}
\hline Correlated traits $^{\mathbf{a}}$ & $\mathbf{B W}_{\mathbf{4}}$ & $\mathbf{B W}_{\mathbf{6}}$ & $\mathbf{B W}_{\mathbf{8}}$ & $\mathbf{B W}_{\mathbf{1 2}}$ \\
\hline $\mathbf{B W}_{\mathbf{4}}$ & - & 0.14 & 0.51 & 0.20 \\
& - & $(0.683)$ & $(2.257)$ & $(0.346)$ \\
\hline $\mathbf{B W}_{\mathbf{6}}$ & -0.17 & - & 0.77 & 0.02 \\
& $(0.231)$ & -0.29 & - & $0.579)$ \\
\hline \multirow{2}{*}{$\mathbf{W W}_{\mathbf{8}}$} & $(0.196)$ & $(0.114)$ & 0.02 & $(1.207)$ \\
\hline \multirow{2}{*}{$\mathbf{B W}_{\mathbf{1 2}}$} & -0.75 & 0.00 & 0.08 & - \\
\hline
\end{tabular}

${ }^{\mathrm{a}}$ Body weight at 4, 6, 8, and 12 weeks of age (BW4, BW6, BW8, and BW12, respectively);

Table 3. Estimates of genetic (above diagonal) and environmental (below diagonal) correlations between post weaning average daily gains in rabbits as estimated by Multi-trait animal model

\begin{tabular}{|c|c|c|c|c|}
\hline Correlated traits $^{\mathrm{a}}$ & $\mathrm{ADG}_{4-8}$ & $\mathrm{ADG}_{4-12}$ & ADG $_{8-10}$ & $\mathrm{ADG}_{8-12}$ \\
\hline $\mathbf{A D G}_{4-8}$ & - & $\begin{array}{c}0.13 \\
(2.298)\end{array}$ & $\begin{array}{c}0.53 \\
(5.410)\end{array}$ & $\begin{array}{c}0.08 \\
(2.637)\end{array}$ \\
\hline $\mathbf{A D G}_{4-12}$ & $\begin{array}{c}-0.18 \\
(0.081)\end{array}$ & - & $\begin{array}{c}0.76 \\
(0.338) \\
\end{array}$ & $\begin{array}{c}0.04 \\
(0.385)\end{array}$ \\
\hline $\mathbf{A D G}_{8-10}$ & $\begin{array}{c}0.01 \\
(0.076)\end{array}$ & $\begin{array}{c}0.35 \\
(0.071)\end{array}$ & - & $\begin{array}{c}0.02 \\
(0.360)\end{array}$ \\
\hline $\mathrm{ADG}_{8-12}$ & $\begin{array}{c}-0.09 \\
(0.119)\end{array}$ & $\begin{array}{c}1.00 \\
(0.026)\end{array}$ & $\begin{array}{c}0.34 \\
(0.084)\end{array}$ & - \\
\hline
\end{tabular}

${ }^{a}$ Average daily gain between 4-8 weeks interval $\left(\mathrm{ADG}_{4-8}\right), 4-12$ weeks $\left(\mathrm{ADG}_{4-12}\right), 8-10$ weeks $\left(\mathrm{ADG}_{8-10}\right)$, and 8-12 weeks $(\mathrm{ADG} 8-12)$.

\section{Breeding values \\ Body weight}

Estimates of minimum and maximum predicted breeding values (PBV), and their accuracies (r) for BW at various ages estimated from does breeding values (DBVs), bucks breeding values (BBVs) and progeny breeding values (PBVs) were presented in table 4. The range of DBV for BW at four, five, six, eight, 10, and 12 weeks of age were 360, 584, 541, 561, 600, and 232 gram, respectively, and that of BBV were 219, 247, 250, 213, 270, and 290 gram, respectively. Whereas the range of PBV was 517, 575, 550, 505, 535 and 548 gram for BW at 4, 5, 6, 8, 10, and 12 weeks of age, respectively. Table 5 shows the higher numbers of PPVs which were obtained from crossing between bucks of G $\sigma^{\lambda} \mathrm{X}$

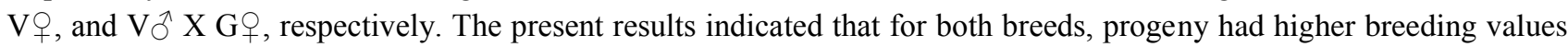

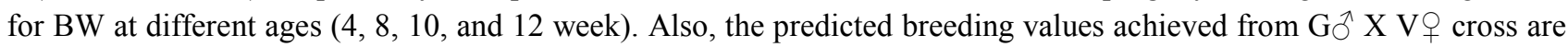
superior to those attained from reciprocal cross. Then, it is important to recognize that there was a potentially moderate

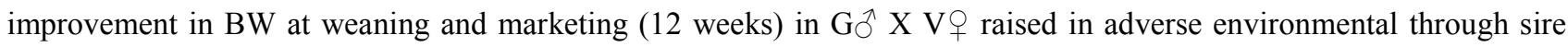
selection. According to high ranges in breeding values for most body weights obtained Does and progeny, indicated the importance of selection of doe and progeny in the second line to improve BW for different ages. The similar results were also obtained by Khalil et al. (2000) and Sabra et al. (2001). Moreover, Khalil et al. (2000) concluded that among all sires in NZW and California breeds, percentage of sires with positive estimates of sire transmitting ability (46.20 to $61.10 \%$ ) for BW (At 5, 6, 8, 10 and 12 weeks). From the genetic point of view, there is a potentially for a moderate improvement in post-weaning growth traits in NZW and Cal rabbits raised in adverse environmental through sire selection. In addition, Sabra et al. (2001) noticed that the PBV for BW at 8 weeks and 12 weeks of age ranged from 269 to 303 grams, and from -315 to 324 grams in NZW, and Z-line. Also, wide variations in PBV of BW between the two strains was found to be in favor of Z-Line rabbits (Iraqi et al., 2002). The exactness of lowest and greatest evaluations of PBV were for the most part higher in NZW than those in Z-Line.

\section{Average daily gain}

Estimates of minimum and maximum PBV with standard errors (SE) and their accuracies (r) for ADG between 4 to 8 weeks $\left(\mathrm{ADG}_{4-8}\right)$, between $4-12$ weeks $\left(\mathrm{ADG}_{4-12}\right)$, between 8 to 10 weeks $\left(\mathrm{ADG}_{8-10}\right)$, and between 8 to 12 weeks $\left(\mathrm{ADG}_{8-12}\right)$ estimated from DBVs, and PBVs are presented in table 6. The range of DBVs were 6.29, 1.845, 8.31, and 11.38 gram for $\mathrm{ADG}_{4-8}, \mathrm{ADG}_{4-12}, \mathrm{ADG}_{8-10}$, and $\mathrm{ADG}_{8-12}$, respectively. Also, the $\mathrm{BBV}$ s for the above-mentioned traits were 3.08, 1.32, 6.11, and 15.29 gram, respectively. Whereas, the range of PBVs were 6.95, 1.86, 6.16, and 15.36 gram, respectively. The present results indicated that the range of predicted breeding values of does for most traits studied were higher than those of progeny and sires. The obtained results revealed the importance of dams, since it gives the higher range of breeding values and selection of dams for the next generation in maternal line would place emphasis on good genetic maternal effects. Similar results have found where the genetic trend of post-weaning daily gain in lines A and V rabbits, had positive trend, small for line V, and considerably higher for line A (Baselga and García, 2002). 
Table 4. The ranges of predicted breeding values for does, bucks and progeny in weekly body weights from weaning to marketing for Gabali, V-line rabbits and their crosses as estimated by multi-trait animal model

\begin{tabular}{|c|c|c|c|c|c|c|c|c|c|c|c|c|c|c|c|c|c|c|}
\hline \multirow{4}{*}{ Traits ${ }^{\text {a) }}$} & \multicolumn{18}{|c|}{ Predicted breeding values ${ }^{\mathrm{b}}$} \\
\hline & \multicolumn{6}{|c|}{ DBVs } & \multicolumn{6}{|c|}{ BBVs } & \multicolumn{6}{|c|}{ PBVs } \\
\hline & \multicolumn{3}{|c|}{ Minimum } & \multicolumn{3}{|c|}{ Maximum } & \multicolumn{3}{|c|}{ Minimum } & \multicolumn{3}{|c|}{ Maximum } & \multicolumn{3}{|c|}{ Minimum } & \multicolumn{3}{|c|}{ Maximum } \\
\hline & BV & SE & $\mathbf{R}$ & BV & SE & $\mathbf{r}$ & BV & SE & $\mathbf{r}$ & BV & SE & $\mathbf{R}$ & BV & SE & $\mathbf{r}$ & BV & SE & $\mathbf{r}$ \\
\hline $\mathbf{B W}_{4}$ & -0.207 & 0.10 & 0.88 & 0.153 & 0.05 & 0.37 & -0.143 & 0.04 & 0.73 & 0.076 & 0.07 & 0.92 & -0.201 & 0.06 & 0.68 & 0.316 & 0.08 & 0.85 \\
\hline $\mathbf{B W}_{5}$ & -0.241 & 0.05 & 0.37 & 0.343 & 0.11 & 0.88 & -0.174 & 0.05 & 0.73 & 0.073 & 0.08 & 0.91 & -0.223 & 0.07 & 0.00 & 0.352 & 0.11 & 0.85 \\
\hline $\mathrm{BW}_{6}$ & -0.214 & 0.06 & 0.35 & 0.327 & 0.11 & 0.87 & -0.184 & 0.05 & 0.71 & 0.066 & 0.08 & 0.79 & -0.217 & 0.07 & 0.00 & 0.333 & 0.11 & 0.83 \\
\hline $\mathbf{B W}_{8}$ & -0.228 & 0.06 & 0.00 & 0.333 & 0.83 & 0.81 & -0.116 & 0.05 & 0.00 & 0.097 & 0.08 & 0.89 & -0.197 & 0.07 & 0.00 & 0.314 & 0.11 & 0.82 \\
\hline $\mathrm{BW}_{10}$ & -0.254 & 0.07 & 0.00 & 0.346 & 0.13 & 0.80 & -0.141 & 0.06 & 0.39 & 0.129 & 0.12 & 0.89 & -0.229 & 0.08 & 0.00 & 0.323 & 0.13 & 0.84 \\
\hline $\mathrm{BW}_{12}$ & -0.113 & 0.08 & 0.00 & 0.119 & 0.14 & 0.83 & -0.100 & 0.06 & 0.38 & 0.198 & 0.13 & 0.88 & -0.212 & 0.09 & 0.00 & 0.336 & 0.14 & 0.83 \\
\hline
\end{tabular}

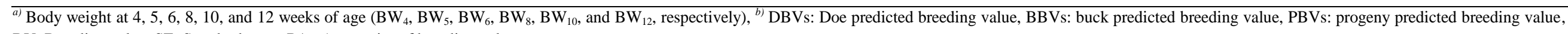
BV: Breeding value, $S E$ : Standard error, R/r: Accuracies of breeding value. 


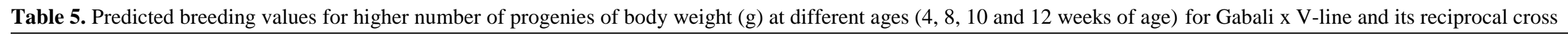

\begin{tabular}{|c|c|c|c|c|c|c|c|c|c|}
\hline \multicolumn{5}{|c|}{ Gabali x V- line $\left(\mathbf{G}^{\Uparrow} \mathbf{X} \mathbf{V} \bigcirc\right)$} & \multicolumn{5}{|c|}{$\mathbf{V}$ - line x Gabali $\left(\mathbf{V} \curvearrowright \mathbf{X} \mathbf{G}_{+}\right)$} \\
\hline No. & $\mathrm{BW}_{4}^{\mathrm{a})}$ & $\mathbf{B W}_{8}$ & $\mathrm{BW}_{10}$ & $\mathrm{BW}_{12}$ & No. & $\mathrm{BW}_{4}$ & $\mathrm{BW}_{8}$ & $\mathbf{B W}_{10}$ & $\mathrm{BW}_{12}$ \\
\hline 100 & -293 & -272 & -197 & -185 & 351 & -185 & -177 & -223 & 214 \\
\hline 101 & 426 & 292 & 601 & 350 & 357 & 120 & 210 & 153 & 112 \\
\hline 216 & 212 & 164 & 253 & 282 & 354 & 136 & 035 & 150 & 164 \\
\hline 274 & 326 & 279 & 285 & 113 & 356 & 040 & 101 & 080 & 122 \\
\hline 277 & 503 & 395 & 552 & 301 & 369 & 013 & 078 & 039 & 059 \\
\hline 279 & 328 & 270 & 320 & 133 & 370 & 104 & 162 & 151 & 173 \\
\hline 282 & 117 & 111 & 067 & 060 & 384 & 024 & 088 & 051 & 069 \\
\hline 301 & 303 & 270 & 237 & 169 & 385 & -113 & -106 & -166 & 240 \\
\hline 387 & 673 & 550 & 676 & 454 & 401 & 071 & 095 & -110 & -152 \\
\hline 910 & 478 & 404 & 440 & 318 & 406 & 220 & 240 & 304 & 374 \\
\hline 915 & 353 & 259 & 445 & 406 & 410 & 036 & 026 & 007 & 053 \\
\hline 960 & 190 & 170 & 145 & 065 & 441 & 097 & 092 & 128 & 145 \\
\hline 967 & 134 & 117 & 107 & 041 & 487 & 087 & 039 & 082 & 090 \\
\hline 4006 & 209 & 155 & 263 & 203 & 489 & 418 & 384 & 573 & 739 \\
\hline 4008 & 678 & 599 & 544 & 378 & 498 & 133 & 192 & 175 & 168 \\
\hline 4009 & -071 & -060 & -068 & -393 & 4055 & 472 & 525 & 654 & 801 \\
\hline 4016 & 130 & 020 & 423 & 257 & 4056 & 354 & 480 & 446 & 390 \\
\hline \multirow[t]{2}{*}{4098} & 270 & 220 & 270 & 068 & 5001 & 044 & 104 & 060 & 038 \\
\hline & & & & & 5002 & 188 & 207 & 268 & 347 \\
\hline
\end{tabular}

${ }^{\text {a) }}$ Body weight at $4,8,10$, and 12 weeks of age $\left(\mathrm{BW}_{4}, \mathrm{BW}_{8}, \mathrm{BW}_{10}, \mathrm{BW}_{12}\right.$, respectively)

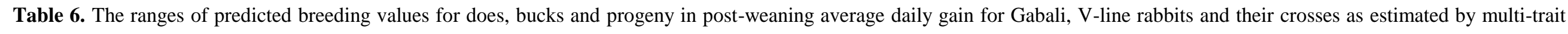
animal model

\begin{tabular}{|c|c|c|c|c|c|c|c|c|c|c|c|c|c|c|c|c|c|c|}
\hline \multirow{4}{*}{ Traits $^{\text {a) }}$} & \multicolumn{18}{|c|}{ Predicted breeding values ${ }^{b}$} \\
\hline & \multicolumn{6}{|c|}{ DBVs } & \multicolumn{6}{|c|}{ BBVs } & \multicolumn{6}{|c|}{ PBVs } \\
\hline & \multicolumn{3}{|c|}{ Minimum } & \multicolumn{3}{|c|}{ Maximum } & \multicolumn{3}{|c|}{ Minimum } & \multicolumn{3}{|c|}{ Maximum } & \multicolumn{3}{|c|}{ Minimum } & \multicolumn{3}{|c|}{ Maximum } \\
\hline & BV & $\mathbf{S E}$ & $\mathbf{R}$ & BV & SE & $\mathbf{r}$ & BV & SE & $\mathbf{r}$ & BV & SE & $\mathbf{R}$ & BV & SE & $\mathbf{r}$ & BV & SE & $\mathbf{r}$ \\
\hline $\mathrm{ADG}_{4-8}$ & -2.850 & 3.58 & 0.16 & 3.444 & 4.460 & 0.61 & -1.421 & 3.12 & 0.40 & 1.656 & 4.15 & 0.72 & -4.542 & 3.77 & 0.32 & 2.404 & 4.30 & 0.63 \\
\hline $\mathbf{A D G}_{4-12}$ & -1.004 & 0.67 & 0.17 & 0.841 & 0.92 & 0.69 & -0.702 & 0.66 & 0.41 & 0.612 & 0.85 & 0.74 & -0.840 & 0.34 & 0.33 & 1.024 & 0.88 & 0.63 \\
\hline $\mathbf{A D G}_{8-10}$ & -3.735 & 2.73 & 0.14 & 4.577 & 3.49 & 0.63 & -2.862 & 2.60 & 0.36 & 3.245 & 3.30 & 0.68 & -2.886 & 0.303 & 0.28 & 3.273 & 3.82 & 0.59 \\
\hline $\mathbf{A D G}_{8-12}$ & -4.590 & 4.31 & 0.23 & 6.786 & 6.58 & 0.77 & -10.25 & 3.88 & 0.51 & 5.032 & 5.81 & 0.82 & -8.327 & 5.15 & 0.43 & 7.033 & 6.090 & 0.72 \\
\hline
\end{tabular}

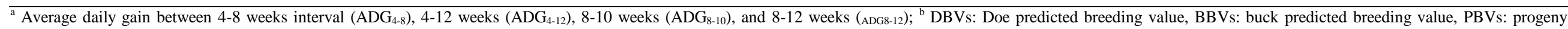
predicted breeding value 


\section{DECLARATIONS}

\section{Competing interests}

There is no conflict of interest.

\section{Authors' contributions}

Rabie T., Khattab A., and Abou-Zeid A. designed research. Rabie T. wrote the paper. Khattab A. and Nowier A. analyzed the data. All authors read and approved the final manuscript.

\section{Acknowledgments}

The support of the Department of Animal Production and Fish Resources, Faculty of Agriculture, Suez Canal University, Ismailia, and the Department of Animal Production, Faculty of Agriculture, Tanta University are gratefully acknowledged.

\section{REFERENCES}

Abou Khadiga G, Saleh K, Nofal R and Baselga M (2008). Genetic evaluation of growth traits in a crossbreeding experiment involving line $\mathrm{V}$ and Baladi Black rabbits in Egypt. $9^{\text {th }}$ World Rabbit CongressVerona- Italy, pp. 23-27. Available at: https://world-rabbit-science.com/WRSA-Proceedings/Congress-2008-Verona/Papers/G-AbouKhadiga.pdf

Anous MR (2000). Genetic improvement of meatiness of local rabbits in Burundi. Egyptian Journal of Rabbit Science, 10: $183-194$. Available at: https://www.cabdirect.org/cabdirect/abstract/20013086105

Argente M-J, Santacreu MA and Blasco A (1999). Phenotypic and genetic parameters of birth weight and weaning weight of rabbits born from unilaterally ovariectomized and intact does. Livestock Production Science, 57: 159-167. DOI https://www.doi.org/10.1016/S0301-6226(98)00166-3

Baselga M and García ML (2002). Evaluating the response to selection in meat rabbit programmes. In Proc.3rd International Conference on Rabbit Production in Hot Climates, October 8-11, Hurghada, Egypt, PP 1-10. Available at: https://riunet.upv.es/handle/10251/9933

Boldman KC, Kriese L, Van Vleck LD, Van Tassell CP and Kachman SD (1995). A manual for use of MTDFREML. A set of programs to obtain estimates of variances and covariances; US Department of Agriculture, Agricultural Research Service, Clay Center, NE, USA.

Chineke CA and Raheem MA (2009). Heritability Estimates of Rabbit litter and linear body traits at pre and post weaning in the Humid Tropics. Proceedings of the $34^{\text {th }}$ Annual Conference of the NSAP, Uyo Nigeria. Available at: https://trove.nla.gov.au/version/254118198

El-Kelany M (2005). Selection indexes for some economic traits on rabbits [master's thesis]. Tanta, Egypt: Tanta University.

El-Raffa AM (2005). Genetic and non-genetic relationships between growth performance and litter size traits in a maternal rabbit line. Egyptian Poultry Science Journal, 25: 1203-1215.

Enab AA, El-Weshahy OA and Abdou FH (2000). Genetic analysis of some economic traits in rabbits. Egyptian Journal of Rabbit Science, 102: 327-339. Abstract Available at: https://www.cabdirect.org/cabdirect/abstract/20013086118

Food and Agriculture Organization (FAO) (2011). World Census of Agriculture: analysis and international comparison of the results (1996-2005). FAO Statistical Development Series No. 13. Rome. Available at: http://www.fao.org/3/i2401e/i2401e00.pdf

Franzese M and Iuliano A (2019). Correlation Analysis, Encyclopedia of Bioinformatics and Computational Biology, pp. $706-721$. DOI: https://www.doi.org/10.1016/B978-0-12-809633-8.20358-0.

García ML and Baselga M (2002). Genetic response to selection for reproductive performance in a maternal line of rabbits. World Rabbit Science, 10: 71-76. DOI: https://www.doi.org/10.4995/wrs.2002.478

Gharib MG (2008). A study of some productive and reproductive traits in two strains of rabbits and their crosses (dissertation). AlAzhar University, Cairo, Egypt.

Gorbani A and Salamatdoust NR (2011). Comparison of the best breed combination in Iranian Holstein and Brown Swiss crossbred dairy cattle for production traits. African Journal of Biotechnology,10: 19836-19839. DOI: https://www.doi.org/10.5897/AJB11.1579

Herbert U (2011). Unending seeds and waters of animal life. 12th Inaugural lecture series of Michael Okpara University of Agriculture, Umudike, Nigeria; pp 1-41. Available at: https://scholar.google.com/scholar?q=Herbert

Iraqi MM (2008). Estimation of Genetic parameters for post-weaning growth traits of Gabali rabbits in Egypt. Livestock Research for Rural Development, 20: Article 69. Available at: http://www.lrrd.org/lrrd20/5/iraq20069.htm

Iraqi MM, Youssef YMK, El-Raffa AM and Khalil MH (2002). Genetic and environmental trends for post-weaning body weights in New Zealand White and Z-line rabbits using the animal model approach. The $3^{\text {rd }}$ Scientific Conference on Rabbit Production in Hot Climates, Hurghada, Egypt. pp 89-101. Available at: http://www.bu.edu.eg/portal/uploads/Agriculture/

Khalil MH (1986). Estimation of genetic and phenotypic parameters for some productive traits in rabbits. [dissertation]. Banha, Egypt: Moshtohor, Zagazig University.

Khalil MH, Ibrahim MK, Youssef YMK and El-Deighadi AS (2000). Estimation of sire transmitting abilities for post-weaning growth traits in New Zealand White and California rabbits raised in the adverse hot climate of Egyptian conditions using an animal model. Egypt Poultry Science Journal, 20: 65-90. 
Lukefahr SD, Odi HB and Atakora JKA (1996). Mass selection for 70-day body weight in rabbit. Journal of Animal Science, 74:14811489. DOI: https://www.doi.org/10.2527/1996.7471481x

Makkar HP, Tran G, Heuzeand V and Ankers P (2014). State-of-the-art on use of insects as animal feed. Animal Feed Science and Technology, 197: 1-33. DOI: https://www.doi.org/10.1016/j.anifeedsci.2014.07.008

Obike OM and Ibe SN (2010). Effect of genotype on pre-weaning growth performance of domestic rabbit in a Humid tropical environment. Glob Vet, 4:388-393. Available at: http://www.idosi.org/gv/gv4(4)10/12.pdf

Okoro VMO, Ogundu UE, Okoli IC, Anyanwu GA, Chikaire J, Raji AO and Maduka CG (2012). Estimation of Heritability and Repeatability for Pre-Weaning and Post Weaning Litter Weights of Unselected Domestic Rabbits in South Eastern Nigeria. International Journal of Agriculture and Forestry, 2: 7-10. DOI: https://www.doi.org/10.5923/j.ijaf.20120201.02

Orengo J, Piles M, Rafel O, Ramon J and Gómez EA (2009). Crossbreeding parameters for growth and feed consumption traits from a five diallel. Journal of Animal Science, 87: 1896-1905. DOI: https://www.doi.org/10.2527/jas.2008-1029

Organization for Economic Co-operation and Development and Food and Agriculture Organization (OECD/FAO) (2017). Agricultural Outlook 2017-2026, OECD Publishing, Paris. DOI: https://doi.org/10.1787/agr_outlook-2017-en.

Piles M, Rafel O, Ramón J and Gómez EA (2004). Crossbreeding parameters of some productive traits in meat rabbits. World Rabbit Science, 7: 59-64. DOI: https://www.doi.org/10.4995/wrs.2004.575

Ragab M, Sánchez JP and Baselga M (2015). Effective population size and inbreeding depression on litter size in rabbits, A case study. Journal of Animal Breeding and Genetics, 132: 68-73. DOI: https://www.doi.org/10.1111/jbg.12110

Sabra ZA, Khalil MH, Hanafi M and Gad HA (2001). Estimation of sire and paternal grand dams breeding values for growth traits in New Zealand White and Californian rabbits using the animal model. Egyptian Journal Rabbit Science, 11: 103-114.

Shebl MK, El-Raffa AM, Zahed SM, Khalil MH and Zimmermann E (1997). Genetic analysis and sire evaluation for post weaning growth traits in three lines of rabbits raised under intensive production system. Egyptian Poultry Science Journal, 17: 235-260. 